\title{
A comparison of two biomaterial carriers for osteogenic protein-1 (BMP-7) in an ovine critical defect model
}

G. E. Pluhar,

A. S. Turner,

A. R. Pierce,

C. A. Toth,

D. L. Wheeler

From University of

Minnesota, Saint

Paul, Minnesota, USA

G. E. Pluhar, DVM, MS, PhD, Assistant Professor Department of Veterinary Clinical Sciences

University of Minnesota, 1352

Boyd Avenue, St. Paul,

Minnesota 55108, USA.

A. S. Turner, BVSc, MS, Professor

Department of Clinical Sciences Colorado State University, 300

West Drake Road, Ft. Collins,

Colorado 80523, USA.

A. R. Pierce, BS, Manager of Toxicology

Stryker Biotech, 35 South

Street, Hopkinton,

Massachusetts 01748, USA.

in C. A. Toth, PhD, Vice

President Research \&

Development

Anika Therapeutics, $160 \mathrm{New}$

Boston Street, Woburn,

Massachusetts 01801, USA.

D. L. Wheeler, PhD, Senior Scientist Preclinical Services Charles River Laboratories Interventional and Surgica

Services, 236 Blackmer Road Southbridge, Massachusetts 01550, USA.

Correspondence should be sent to Dr G. E. Pluhar; e-mail: pluha006@umn.edu

(C2006 British Editorial Society of Bone and Joint Surgery doi:10.1302/0301-620X.88B7. $17056 \$ 2.00$

$J$ Bone Joint Surg $[\mathrm{Br}]$ 2006;88-B:960-6.

Received 8 August 2005

Accepted after revision

8 February 2006

Critical size defects in ovine tibiae, stabilised with intramedullary interlocking nails, were used to assess whether the addition of carboxymethylcellulose to the standard osteogenic protein-1 (OP-1/BMP-7) implant would affect the implant's efficacy for bone regeneration. The biomaterial carriers were a 'putty' carrier of carboxymethylcellulose and bovinederived type-I collagen (OPP) or the standard with collagen alone (OPC). These two treatments were also compared to "ungrafted" negative controls. Efficacy of regeneration was determined using radiological, biomechanical and histological evaluations after four months of healing. The defects, filled with OPP and OPC, demonstrated radiodense material spanning the defect after one month of healing, with radiographic evidence of recorticalisation and remodelling by two months. The OPP and OPC treatment groups had equivalent structural and material properties that were significantly greater than those in the ungrafted controls. The structural properties of the OPP- and OPC-treated limbs were equivalent to those of the contralateral untreated $\operatorname{limb}(p>0.05)$, yet material properties were inferior $(p<0.05)$. Histopathology revealed no residual inflammatory response to the biomaterial carriers or OP-1. The OPP- and OPC-treated animals had $60 \%$ to $85 \%$ lamellar bone within the defect, and less than $25 \%$ of the regenerate was composed of fibrous tissue. The defects in the untreated control animals contained less than $40 \%$ lamellar bone and more than $60 \%$ was fibrous tissue, creating full cortical thickness defects. In our studies carboxymethylcellulose did not adversely affect the capacity of the standard OP-1 implant for regenerating bone.

The regeneration of bone in large skeletal defects, especially in load-bearing areas, is clinically challenging. Such defects have been treated with either autogenous bone, which is available in limited amounts and necessitates a second surgical site with associated morbidity, ${ }^{1}$ or with allogenic bone. However, this has minimal osteoinductive capacity, immunogenic potential, ${ }^{2-4}$ potential for disease transmission $^{5,6}$ and is minimally replaced by new host bone. ${ }^{7-10}$ Long-term failure following massive cortical allografting is commonly caused by fracture of the graft, nonunion of the grafthost bone junction, or infection. ${ }^{7,11-16}$ An alternative to conventional bone grafting is the use of osteoinductive proteins, such as bone morphogenetic proteins (BMP). Osteogenic protein-1 (OP-1), also known as BMP-7 has proved to be efficacious in healing large osseous defects, both in animal models and in human clinical trials. ${ }^{17-25}$

BMPs initiate a cascade of events that involve chemotaxis and differentiation of pluripotent progenitor cells into bone-forming cell lines, leading to de novo bone formation. ${ }^{26}$ The efficacy of OP-1 depends on the sustained delivery of adequate concentrations of the protein to the desired site, making the carrier a crucial component. In addition to optimising the release of OP-1 at the defect site, the ideal delivery vehicle would serve as an osteoconductive scaffold, with appropriate porosity for infiltration and colonisation of the recruited osteogenic cells. The vehicle should also be resorbed or biodegraded as new bone matrix is formed and prevent soft tissue that might hinder subsequent filling with bone from encroaching into the defect. It should also be biocompatible to minimise inflammatory or immunogenic reactions.

Many preclinical studies have reported the successful repair of skeletal defects using purified collagen in particulate, sponge or gel form to deliver BMPs. ${ }^{17,18,22,23}$ Although these carriers have proved to fulfil many of the criteria of the perfect delivery vehicle, their handling properties are not ideal. Proper haemostasis and fixation techniques are necessary to ensure 
containment of the device at the treatment site. A composite carrier with a putty-like consistency would enable the surgeon to mould the material to fit the defect and would provide better retention within the site without relying on soft-tissue envelopes to retain the carrier. Carboxymethylcellulose (CMC) was chosen to be added to purified bovine type-I collagen, to produce a carrier with unique physical characteristics.

$\mathrm{CMC}$ is a semi-synthetic, anionic water-soluble polymer derived from cellulose. It dissolves rapidly in water, is physiologically inert, and acts as a water binder, thickener and suspending or rheology agent. It is available in standard, food and pharmaceutical grades. CMC has been used alone in vivo, or with other polymers in vitro, as a matrix for the delivery of osteoinductive proteins. ${ }^{15,27,28}$ This biodegradable polymer increases the viscosity and cohesiveness of the delivery vehicle and can modify the release kinetics of certain drugs by acting as a diffusion barrier. ${ }^{29,30}$

The primary aim of this study was to assess whether the addition of CMC to the standard OP-1 implant (OPP) would reduce the efficacy of bone regeneration compared with the standard OP-1 implant without CMC (OPC). The healing of the defect was assessed by serial radiography, histology and post-mortem mechanical testing in torsion. Both treatments were compared biomechanically to positive (intact contralateral limb) and ungrafted negative (empty defect) controls. We hypothesised that the CMC biomaterial carrier would act only as a binder, improving the handling characteristics of the type-I collagen particles in the OP-1 implant, and not adversely affect the known boneforming capacity of the standard OP-1 implant and the quality of the regenerated bone within the defect.

\section{Materials and Methods}

We used 26 skeletally mature ewes with a mean body weight of $70 \mathrm{~kg}$ in the study. The sheep were cared for in accordance with the guidelines of, and in an animal facility approved by, the Institutional Animal Care and Use Committee. Anaesthesia was induced with intravenous ketamine $(2.2 \mathrm{mg} / \mathrm{kg})$ and diazepam $(0.1 \mathrm{mg} / \mathrm{kg})$ and maintained by isoflurane and oxygen inhalation after endotracheal intubation. Prophylactic cephazolin antibiotic $1 \mathrm{~g}$ intravenously) was given at induction and at the end of surgery. The surgical procedure involved a medial approach to the tibia and removal of a $5 \mathrm{~cm}$ mid-diaphyseal osteoperiosteal segment. The distal bone segment was reamed with $6 \mathrm{~mm}$ and $8 \mathrm{~mm}$ reamers until an $8 \mathrm{~mm}$ nail could be accommodated. If fissures developed during reaming, $18 \mathrm{~g}$ full cerclage wires were placed to minimise propagation. The tibial length was maintained with a custom $5 \mathrm{~cm}$ spacing jig, and the proximal and distal ends were stabilised using an intramedullary interlocking nail (Innovative Animal Products, Rochester, Minnesota) with two $4.5 \mathrm{~mm}$ cortical screws at each end. We assigned the animals, using a completely randomised design, to one of three treatment groups. Ten sheep had $3.5 \mathrm{mg}$ recombinant human (rh)
OP-1 formulated with $1 \mathrm{~g}$ of particulate type- 1 bovine bone collagen (OP-1, Implant, Stryker Biotech, Hopkinton, Massachusetts) (OPC); a further group of ten sheep were treated with $3.5 \mathrm{mg}$ rh OP- 1 with $1 \mathrm{~g}$ of type- 1 bone collagen and $3 \mathrm{ml}$ of CMC (OP-1 Putty, Stryker Biotech, Hopkinton, Massachusetts) (OPP). A negative control group of six sheep were left with an empty ungrafted defect. The muscle fascia and subcutaneous tissues were closed with $2 /$ 0 absorbable synthetic sutures, the skin edges apposed with 2/0 nylon, and a soft-padded bandage placed for five to seven days. Transdermal fentanyl patches $(150 \mu \mathrm{g} / \mathrm{hr})$ and oral phenylbutazone ( $1 \mathrm{~g}$ once daily) were used for 72 hours after surgery to minimise pain and inflammation. The sheep were kept in pens for the duration of the study in order to limit their activity, and were examined twice daily for signs of pain and ability to weight-bear.

Radiological analysis. Mediolateral radiographs were taken immediately after surgery to document the position of the defect and to confirm correct nail placement. Five sheep from each OP-1 treatment group were selected to have tibial radiographs repeated monthly until killed, so that the progress of bone regeneration and remodelling could be assessed. All animals had standard orthogonal radiographs of the tibia taken at death four months after surgery.

Biomechanical testing. The operated tibia and the contralateral intact control tibia were harvested and stripped of soft tissues. Digital photographs and contact radiographs were taken. The interlocking screws and intramedullary nails were carefully removed and the tibiae were wrapped in saline-soaked sponges and plastic wrap to retain moisture during biomechanical preparation. The distal and proximal tibiae were transected to maintain a consistent gauge length of $15 \mathrm{~cm}$, with the defect centrally located within this length. The diameter of the diaphysis in the central defect was measured with digital calipers in mediolateral and craniocaudal planes. Antirotational screws were placed into the proximal and distal tibial metaphyses. The specimens were secured in aluminium boxes using high-strength potting resin (Dynacast potting material \#960DTGU-Green; Kindt-Collins Co, Cleveland, Ohio) using a custom-aligning fixture to ensure that rotation occurred about the longitudinal axis of the tibia. The resin was allowed to set for at least two hours prior to testing. Potting boxes were secured to a servohydraulic materials testing system (MTS Bionix 858; MTS, Eden Prairie, Minnesota) in a custom-designed jig. Axial torque was applied at an angular displacement rate of $10 \mathrm{rad} / \mathrm{s}$ in internal rotation (anticlockwise for right limbs and clockwise for left limbs). Torque and angular displacement data were collected at $100 \mathrm{~Hz}$. The mode of failure was documented by taking digital photographs of the specimens. The diameter of the tibia and cortical thickness at the site of failure was measured at intervals of $20^{\circ}$ around the circumference of the bone using a digital caliper. Geometric measurements and acquired load-displacement data were used to calculate polar moment of inertia, torsional strength, torsional 
Table I. Rating scheme (developed by authors) for evaluation of histological specimens

\begin{tabular}{|c|c|c|c|c|c|}
\hline Score & $\begin{array}{l}\text { Presence of } \\
\text { inflammatory cells* }\end{array}$ & Tissue type & Bone remodelling & $\begin{array}{l}\text { Presence of } \\
\text { implant material }\end{array}$ & Bone bridging \\
\hline 0 & None & $100 \%$ fibrous/cartilaginous & $100 \%$ woven & No & Complete \\
\hline 1 & Some & $\begin{array}{l}\geq 75 \% \text { fibrous/cartilaginous; } \\
<25 \% \text { bone }\end{array}$ & $\begin{array}{l}\geq 75 \% \text { woven; } \\
<25 \% \text { lamellar }\end{array}$ & Yes & Defect in 1 cortex \\
\hline 2 & Many & $\begin{array}{l}\geq 50 \% \text { fibrous/cartilaginous; } \\
<50 \% \text { bone }\end{array}$ & $\begin{array}{l}\geq 50 \% \text { woven; } \\
<50 \% \text { lamellar }\end{array}$ & $\mathrm{N} / \mathrm{A}$ & Defect in 2 cortices \\
\hline 3 & $\mathrm{~N} / \mathrm{A}$ & $\begin{array}{l}\geq 25 \% \text { fibrous/cartilaginous; } \\
<75 \% \text { bone }\end{array}$ & $\begin{array}{l}\geq 25 \% \text { woven; } \\
<75 \% \text { lamellar }\end{array}$ & $\mathrm{N} / \mathrm{A}$ & $N / A$ \\
\hline 4 & $\mathrm{~N} / \mathrm{A}$ & $100 \%$ bone & $100 \%$ lamellar & $\mathrm{N} / \mathrm{A}$ & $\mathrm{N} / \mathrm{A}$ \\
\hline
\end{tabular}

modulus, energy absorbed at failure and torsional stiffness.

Decalcified histology. After biomechanical testing the specimens were bisected sagittally and the lateral portions were fixed in $10 \%$ neutral buffered formalin and decalcified in rapid decalcification solution. The specimens were trimmed to a thickness of $2 \mathrm{~mm}$ prior to processing to allow the solutions to penetrate adequately. The tissues were processed, using a custom programme for large samples (Thermo Shandon Inc., Pittsburg, Pennsylvania), and embedded in paraffin. Serial sagittal sections were cut using a rotary microtome (Thermo Shandon Inc.) and stained with haematoxylin and eosin. The specimens were subjectively graded in blinded fashion by two investigators using a rating scheme for the presence of inflammatory cells, distribution of tissue type, bone remodelling, the presence of implant material and the extent of cortical defects, as shown in Table I.

Statistical analysis. One-way analysis of variance (ANOVA) was used to compare the differences between experimental groups for the biomechanical testing parameters: torque, angular displacement, torsional strength, torsional stiffness, shear modulus and energy to failure. When there were significant differences among groups, Duncan's multiple comparison tests ${ }^{31}$ were used to determine which treatments were different (i.e. OPP $v s$ OPC, OPP $v s$ negative control etc). The statistical significance level was set at $\alpha=$ 0.05 and power was estimated to be $\geq 80 \%$, based on the sample size of ten. A Kruskal-Wallis one-way ANOVA and distribution-free multiple comparisons were performed on the data from the histological analysis. Differences were considered significant at $\alpha=0.02$ to increase stringency owing to the number of between-group comparisons. All statistical analyses were run using SAS statistical software (SAS, Cary, North Carolina).

\section{Results}

Fissures developed in the cortical bone of the distal tibia during reaming and implantation of the nails in five of 26 tibiae and required wiring. The putty implant was generally more cohesive and less granular than the collagen implant and tended to adhere to itself, but not to the surgeon's gloves. The putty implant material could be shaped into cylinders that surrounded the interlocking nail in the defect site more readily than the standard collagen implant. There was no attempt to create a circumferential soft-tissue envelope around the implant material. All sheep were partially weight-bearing on the operated limb 12 hours after surgery and had increased use of their limbs with time. There were no systemic toxic effects from either OP-1 biomaterial carriers.

Radiological analysis. The biomaterial carrier and defects were radiolucent, so it was not possible to determine whether any of the implant material migrated from the defect site after the animals started to walk. Radiodense material was noted to span the entire defect in all OPC- and OPP-treated animals after one month. The quantity of radiodense material in the defects increased over time and appeared to remodel towards a distinct cortical shell as early as two months after surgery for OPC- and OPPtreated animals (Fig. 1). Some radiodense material was noted in the defects of negative controls, yet some voids remained and complete bridging was not realised by four months in most animals. There was more bone formation than expected in the negative control group.

Mechanical testing. No significant differences in peak torque, stiffness, energy absorbed at failure or angular displacement were noted between OPC- and OPP-treated tibia ( $p>0.05$ ). OPC, OPP and intact contralateral controls had equivalent peak torque $(\mathrm{p}>0.05)$ and this was significantly greater than in the ungrafted negative controls $(\mathrm{p}=0.003)$. There were significant differences in torsional stiffness between the groups $(\mathrm{p}=0.0001)$. Stiffness was significantly greater for contralateral control than for all other treatments, and OPP and OPC stiffnesses were significantly greater than in ungrafted negative controls. Total energy absorbed at failure for the OP- 1 specimens was significantly greater than in the negative controls $(p<0.05)$. The intact tibiae had significantly less angular displacement than did OPP- and OPC-treated tibiae $(\mathrm{p}=0.01)$. 


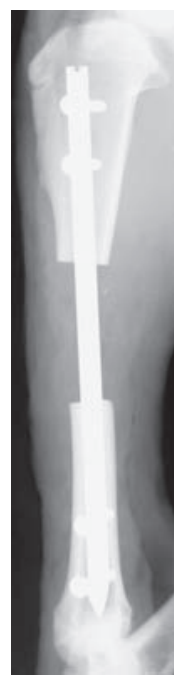

0 month

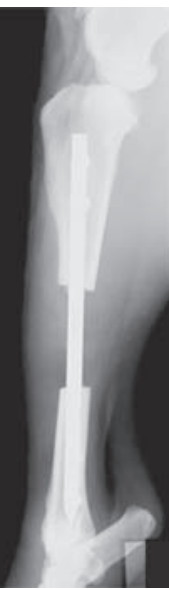

0 month

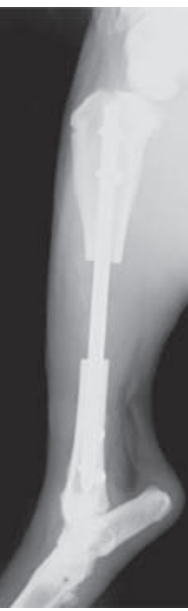

0 month

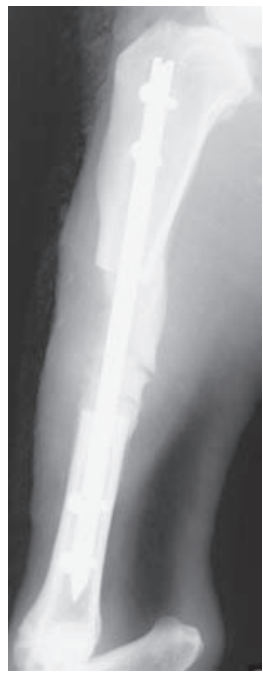

2 months

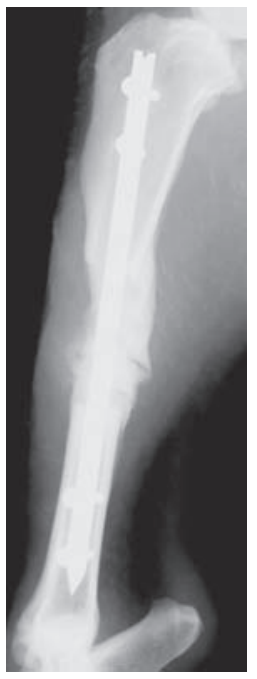

3 months

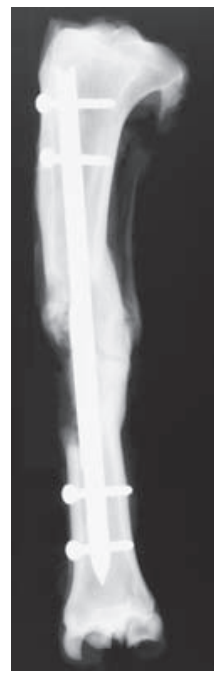

4 months

Fig. 1a

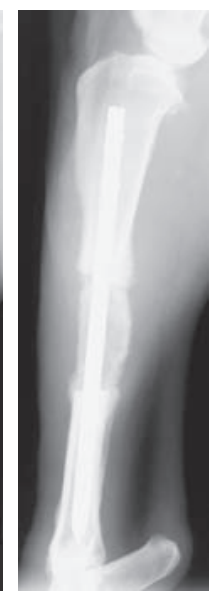

1 month

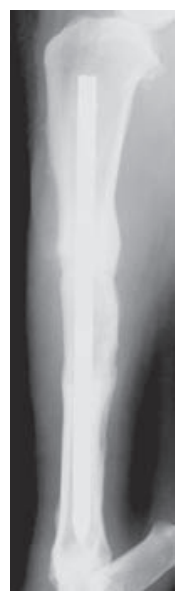

2 months

Fig. 1b

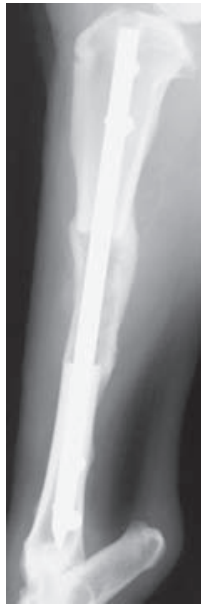

1 month

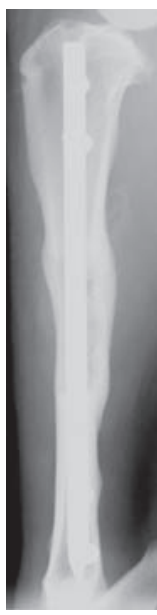

2 months

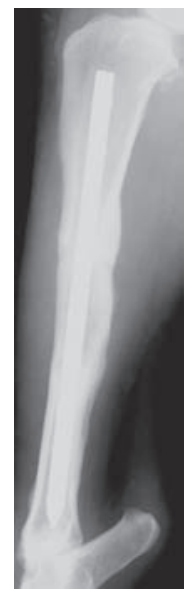

3 months

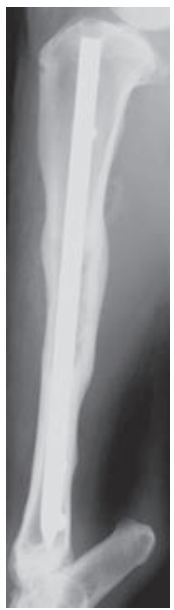

3 months

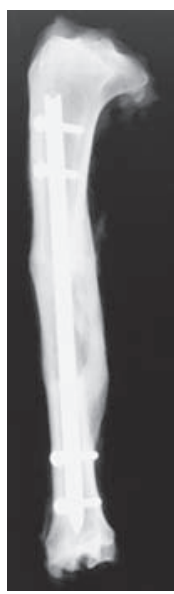

4 months

Fig. 1c

Radiological composites of serial images of a) a negative control tibia at 0, 2, 3 and 4 months after surgery b) an OPC-treated tibia at $0,1,2,3$ and 4 months after surgery, and c) an OPP. treated tibia at $0,1,2,3$, and 4 months after surgery, demonstrating the progression of the defect filling with bone. The four-month images are post-mortem contact radiographs. 
Table II. Histological grading of regenerate tissue in specimen defects

\begin{tabular}{lllll}
\hline Treatment group & $\begin{array}{l}\text { Number of } \\
\text { specimens }\end{array}$ & $\begin{array}{l}\text { Bone, cartilage and } \\
\text { fibrous tissue (\%) }\end{array}$ & $\begin{array}{l}\text { Bone } \\
\text { remodelling }\end{array}$ & $\begin{array}{l}\text { Full cortical } \\
\text { defects }\end{array}$ \\
\hline Negative controls & 6 & 1.75 & 1.75 & 1.5 \\
OPC & 10 & 3 & 2.5 & 0 \\
OPP & 10 & 4 & 3.5 & 0
\end{tabular}

All values represent the median score for that group. For bone, cartilage and fibrous tissue a score of $4=100 \%$ bone; for bone remodelling a score of $4=100 \%$ remodelled lamellar bone; and for extent of cortical defects 2 = full-thickness defects in both cortices examined

* OPC, OP-1 standard with collagen alone; OPP, OP-1 with carboxymethylcellulose and bovine-derived type-1 collagen

The material properties for one negative control specimen were omitted from the statistical calculations. The polar moment of inertia for that specimen was five orders of magnitude smaller than the others in that group, owing to the lack of tissue in the defect affecting its geometry. Torsional strength and torsional or shear stiffness of the intact tibiae were significantly greater than in both the OP-1 specimens and the negative controls $(\mathrm{p}=0.0001)$.

Histological analysis. The median grading scores for each histological parameter are summarised in Table II. Although the OPP implant sites were graded slightly better than OPC sites, OPC and OPP tibial defects had equivalent histological scores for all parameters $(\mathrm{p}>0.05)$. Regardless of the biomaterial carrier, OP-1-treated defect sites had bridging woven bone actively remodelling to lamellar bone. The negative control tibial defects were not completely bridged with osseous tissue and were composed of fibrous connective tissue, immature woven bone and cartilage. Full-thickness defects filled with fibrous tissue in one or both of the regenerating cortices were seen in all negative control specimens. Only the OPP group had significantly more bone that had remodelled into lamella than the negative control group $(\mathrm{p}<0.02)$. The collagen carrier with or without CMC appears to resorb as new bone fills the defect. None of the carrier was seen in any specimen, except for a very small amount in a single OPC defect. Although we cannot definitively state that the carrier does not cause an inflammatory reaction in the early post-operative period, no evidence of inflammation was seen in any of the defects, including that with the small amount of residual carrier.

\section{Discussion}

The addition of the binding agent CMC did not adversely affect the healing capability of the OP-1 implant (OP-1 with type-I bovine collagen). The regenerate bone from OPC and OPP treatments was equivalent radiologically, mechanically and histologically after four months of healing. The handling characteristics of the 'putty' were felt to be superior to those of the standard collagen carrier. The 'putty' was easier to mould, tended to adhere to itself rather than to instruments or surgeon's gloves, and remained in the defect more readily than the collagen carrier.

Purified sodium CMC has been shown to have no systemic toxic properties with subacute and chronic oral administration in rats, guinea pigs, dogs and humans. ${ }^{32}$
There were no systemic toxic effects of either biomaterial carrier in our study. Other studies that placed CMC in osseous or chondral defects did not report local or systemic toxicity, ${ }^{15,27,33,34}$ but alkaline phosphatase activity was stimulated in fibroblast cultures. ${ }^{28}$

All defects treated with OP-1 were seen to be almost completely filled with radiodense material one month after surgery. Progressive healing of the defects was seen on serial monthly radiographs until a column of dense bone with a central canal was observed three to four months after surgery. The dense material seen to be filling the defects was assumed to be regenerating bone undergoing lamellar remodelling. This assumption was confirmed by histological evaluation of the tissue at four months.

An unexpected finding was the amount of new bone that developed in some of the untreated control defects. A critical-sized defect, 1.5 to 2.0 times the diaphyseal diameter, should, by definition, develop into a nonunion if left untreated. ${ }^{35,36}$ Our findings are similar to those of den Boer et al, ${ }^{37}$ who found union in $33 \%$ of sheep with an untreated defect that was 1.8 times the shaft diameter. The relative stability of interlocking nail fixation and the inability to remove the periosteum from the defect site were thought to be contributing factors for union of those critical defects. Those authors suggested that a critical defect in sheep tibia stabilised with an interlocking nail should be at least twice the shaft diameter. The defects in this study were 2.5 times the shaft diameter and were classified radiologically and histologically as delayed unions or fibrous nonunions. Because of the amount of bone that did form, it was hypothesised that some of the periosteal tissue may have been elevated with the surrounding muscle fascia and left in situ when the cortical defects were made, allowing more bone production than would occur in a defect completely devoid of periosteum. Negative controls in subsequent studies using this ovine model with meticulous removal of the periosteum did not form a significant amount of bone in the defects after three months. ${ }^{38,39}$

Biomechanical analysis of the specimens showed equivalence in structural properties between the OPC and OPP treatments. Mechanical integrity of the OP-1-treated tibial defects at four months was statistically equal to the contralateral unoperated normal bone and superior to the negative controls. However, the regenerated bone in the OP-1treated defects had not yet remodelled sufficiently to 
achieve material properties that were equal to those of the contralateral controls. Radiological evidence of healing, correlating with the structural integrity of the grafted defect site is an important clinical finding. Complete remodelling of the woven bone and re-orientation of the lamellae with the original osteonal lamellae of the host cortices had not occurred after four months. Continued functional remodelling of the bone in response to the stresses placed upon it would be expected in this load-bearing bone to produce regenerate bone more similar to host bone. ${ }^{40}$ Until that time, the geometry of the callus of healing bone compensated for the developing material properties of the tissue to provide a clinically functional weight-bearing bone.

There has been much discussion on the validity of animal models in musculoskeletal research, especially with small mammals such as rodents and rabbits that may have greater potential for bone healing and heal more rapidly than humans. Larger animals such as sheep, goats and dogs may be better models for testing potential products for humans as their healing rates are closer to those observed clinically. The amount of OP-1 used in this study, $3.5 \mathrm{mg}$ for a defect volume of approximately $10.0 \mathrm{~cm}^{3}$, is comparable to that used in previous defect healing studies ${ }^{19-21,25}$ in variety of species. Despite the success of this and other preclinical studies $^{19-21,25}$ showing the efficacy of OP-1 for healing bone defects in various animal models, care must be taken in extrapolating these results to human clinical use. The clinical results of several OP-1 implant (OPC) trials in long bone defects or nonunion have been published, the results of which demonstrate OP-1 to be comparable to autograft bone treatment. ${ }^{22-24,41,42} \mathrm{~A}$ recent study of fusion of the spine found that the final concentration of rhBMP-2 was more critical than the total dose. ${ }^{43}$

In conclusion, this study provides evidence of the ability of OP-1 to regenerate bone in critical-sized defects that was unaffected by the addition of CMC to the standard OP-1 carrier. CMC did not affect the osteoinductive potential of OP-1. The collagen-CMC carrier has excellent handling characteristics and appears to contain the OP-1 in the defect more easily.

Funding for this work was provided by Stryker Biotech. The authors would like to thank Breton Line for mechanical testing and Michael Karr for histological preparation.

No benefits in any form have been received or will be received from a com mercial party related directly or indirectly to the subject of this article.

\section{References}

1. Younger EM, Chapman MW. Morbidity at bone graft donor sites. J Orthop Trauma 1989;3:192-5

2. Bos GD, Goldberg VM, Powell AE, Heiple KG, Zika JM. The effect of histocompatibility matching on canine frozen bone allografts. J Bone Joint Surg [Am] 1983; 65-A:89-96.

3. Bos GD, Goldberg VM, Zika JM, Heiple KG Powell AE. Immune responses of rats to frozen bone allografts. J Bone Joint Surg [Am] 1983;65-A:239-46.

4. Goldberg VM, Stevenson S. Natural history of autografts and allografts. Clin Orthop 1987;225:7-16.

5. Buck BE, Resnick L, Shah SM, Malinin TI. Human immunodeficiency virus cultured from bone: implications for transplantation. Clin Orthop 1990;251:249-53.

6. Nemzek JA, Arnoczky SP, Swenson CL. Retroviral transmission in bone allotransplantation: the effects of tissue processing. Clin Orthop 1996;324:275-82
7. Enneking WF, Campanacci DA. Retrieved human allografts: a clinicopathological study. J Bone Joint Surg [Am] 2001;83-A:971-86.

8. Enneking WF, Mindell ER. Observations on massive retrieved human allografts, J Bone Joint Surg [Am] 1991;73-A:1123-42

9. Gouin F, Passuti N, Verriele V, Delecrin J, Bainvel JV. Histological features of large bone allografts. J Bone Joint Surg [Br] 1996;78-B:38-41.

10. Wheeler DL, Enneking WF. Allograft bone decreases in strength in vivo over time. Clin Orthop 2005;435:36-42.

11. Berrey BH Jr, Lord CF, Gebhardt MC, Mankin HJ. Fractures of allografts: frequency, treatment, and end-results. J Bone Joint Surg [Am] 1990;72-A:825-33.

12. Mankin HJ Doppelt S, Tomford W. Clinical experience with allograft transplantation: the first ten years. Clin Orthop 1983;174:69-86.

13. McDonald DJ, Maguire MH. Complications of large fragment allografts. In: Brown $\mathrm{KLB}$, eds. Complications of limb salvage: prevention, management and outcome. 6th International Symposium, Montreal: ISOLS, 1991:25-8.

14. Thompson RC Jr, Pickvance EA, Garry D. Fractures in large-segment allograft. J Bone Joint Surg [Am] 1993;75-A:1663-73.

15. Woo BH, Fink BF, Page R, et al. Enhancement of bone growth by sustained delivery of recombinant human bone morphogenetic protein-2 in a polymeric matrix. Pharm Res 2001;18:1747-53.

16. Zehr RJ, Enneking WF, Heare T, Liang TS. Fractures in large structural allografts. In: Brown KLB, ed. Complications of limb salvage: prevention, management and out come. 6th International Symposium, Montreal: ISOLS, 1991:3-8,

17. Chen X, Kidder LS, Lew WD. Osteogenic protein-1 induced bone formation in an infected segmental defect in the rat femur. J Orthop Res 2002;20:142-50.

18. Cook SD, Salkeld SL, Patron LP, Sargent MC, Rueger DC. Healing course of primate ulna segmental defects treated with osteogenic protein-1. J Invest Surg 2002; 15:69-79.

19. Cook SD. Preclinical and clinical evaluation of osteogenic protein-1 (BMP-7) in bony sites. Orthopedics 1999;22:669-71.

20. Cook SD, Salkeld SL, Brinker MR, Wolfe MW, Rueger DC. Use of an osteoinductive biomaterial (rhOP-1) in healing large segmental bone defects. J Orthop Trauma 1998;12:407-12.

21. Cullinane DM, Lietman SA, Inoue N, Deitz LW, Chao EYS. The effect of recombinant human osteogenic protein-1 (bone morphogenetic protein-7) impregnation on allografts in a canine intercalary bone defect. J Orthop Res 2002;20:1240-5.

22. Friedlaender GE, Perry CR, Cole JD, et al. Osteogenic protein-1 (bone morphongenetic protein-7) in the treatment of tibial nonunions. J Bone Joint Surg [Am] 2001: 83-A(Suppl 1)(Pt 2):151-8.

23. Geesink RG, Hoefnagels NH, Bulstra SK. Osteogenic activity of OP-1 bone morphogenetic protein (BMP-7) in a human fibular defect. J Bone Joint Surg [Br] 1999; 81-B:710-18.

24. Pecina M, Giltaij LR, Vukicevic S. Orthopaedic applications of osteogenic protein1 (BMP-7). Int Orthop 2001;25:203-8.

25. Salkeld SL, Patron LP, Barrack RL, Cook SD. The effect of osteogenic bone protein-1 on the healing of segmental bone defects treated with autograft or allograft bone. J Bone Joint Surg [Am] 2001;83-A:803-16.

26. Reddi AH, Anderson WA. Collagenous bone matrix-induced endochondral ossification hemopoiesis. J Cell Biol 1976;69:557-72.

27. Aspenberg P, Lohmander LS. Fibroblast growth factor stimulates bone formation: bone induction studied in rats. Acta Orthop Scand 1989;60:473-6.

28. Santa-Comba A, Pereira A, Lemos R, et al. Evaluation of carboxymethylcellulose, hydroxypropylmethylcellulose, and aluminium hydroxide as potential carriers for rhBMP-2. J Biomed Mater Res 2001;55:396-400.

29. Scalia S, Giunchedi P, Pazzi P, Conte U. Enhancement of ursodeoxycholic acid bioavailability by cross-linked sodium carboxymethylcellulose. J Pharm Pharmacol 2000;52:383-8.

30. Ikechukwa Ugwoke M, Kaufmann G, Verbeke N, Kinget R. Intranasal bioavailability of apomorphine from carboxymethylcellulose-based drug delivery systems. Int/ J Pharm 2000;202:125-31.

31. Duncan DB. Multiple range and multiple $\mathrm{F}$ tests. Biometrics 1955;11:1-42.

32. AQUALON ${ }^{\circledR}$ Cellulose Gum (Sodium Carboxymethylcellulose) summary of toxicological investigations. Hercules Incorporated, Bulletin T-123D, 1999.

33. Krukowski M, Snysders RV Jr, Eppley BL, Simmons DJ. Negatively charged resins stimulate bone formation in subperiosteal sites in rats: the effect of age. Clin Orthop 1994;298:266-71.

34. Tacchetti C, Tavella S, Dozin B, et al. Cell condensation in chondrogenic differentiation. Exp Cell Res 1992;200:26-33

35. Key JA. The effect of a local calcium depot on osteogenesis and healing of fractures. $J$ Bone Joint Surg 1934;16:176-84.

36. McBride J, Clyde M, Banks RE, Taylor D, Ryan J. Healing of segmental bone defects in goat tibia [abstract]. J Invest Surg 1993:6:369. 
37. den Boer FC, Patka P, Bakker FC, et al. New segmental long bone defect model in sheep: quantitative analysis of healing with dual energy $\mathrm{x}$-ray absoroptiometry. J Orthop Res 1999;17:654-60.

38. Wheeler DL, Jackinsky SW, Mohr KE, et al. Osteogenic protein-1 (OP-1/BMP-7) enhanced cement as an OP-1 carrier for healing of tibial diaphyseal defects in an ovine model [abstract]. Trans Orthopaedic Research Society, 2004:467.

39. Wheeler DL, Jackinsky SW, Mohr KE, et al. Tricalcium phosphate putty as an OP1 carrier for healing of tibial diaphyseal defects in an ovine model [abstract]. Trans Orthopaedic Research Society, 2004:466.
40. Lanyon LE. Mechanical function and bone remodelling. In: Sumner-Smith G, ed. Bone in clinical orthopaedics. Philadelphia: Saunders, 1982:273-304.

41. Johnson EE, Urist MR. Human bone morphogenetic protein allografting for reconstruction of femoral nonunion. Clin Orthop 2000;371:61-74.

42. Johnson EE, Urist MR. One-stage lengthening of femoral nonunion augmented with human bone morphogenetic protein. Clin Orthop 1998;347:105-16.

43. Suh DY, Boden SD, Louis-Ugbo J, et al. Delivery of recombinant human bone morphogenetic protein-2 using a compression-resistant matrix in posterolateral spine fusion in the rabbit and in the non-human primate. Spine 2002;27:353-60. 